\title{
INFLUÊNCIA DO METAL DE ADIÇÃO NAS PROPRIEDADES MECÂNICAS DO METAL DEPOSITADO DE UM AÇO ESTRUTURAL DE ALTA RESISTÊNCIA
}

\author{
TITLE: INFLUENCE OF FILLER MATERIAL ON MECHANICAL PROPERTIES OF \\ DEPOSITED METAL OF A HIGH-STRENGTH STRUCTURAL STEEL
}

\author{
Douglas Leonardo Camargo Colucci ${ }^{\mathrm{I}}$ \\ Antonio Carlos Muniz Ventura Junior ${ }^{I I}$ \\ Maria Aparecida Bovério ${ }^{\mathrm{III}}$
}

\begin{abstract}
RESUMO
$\mathrm{O}$ presente trabalho visa avaliar a influência do $\mathrm{Nb}$ nas propriedades mecânicas e microestrutural do metal de solda do aço Strenx 700, obtidos com o processo Gas-Shielded Flux Cored Arc Welding (FCAW-G). Foi realizada soldagem multipasse, com préaquecimento de $120^{\circ} \mathrm{C}$ e interpasse $200^{\circ} \mathrm{C}$, na posição plana com energia de soldagem entre $0,70,0,90$ e $1,20 \mathrm{~kJ} / \mathrm{mm}$. O material de adição a ser usado é um eletrodo de alma metálica E81T1 $\mathrm{Nb} \mathrm{G}$, no diâmetro de $1,2 \mathrm{~mm}$, associado à proteção gasosa de $\mathrm{CO}_{2}$. Após a soldagem, foram realizados ensaios de tração, Charpy-V, dureza e metalográficos por microscopia ótica, microanálise por EDS e análise química para caracterização mecânica e microestrutural do metal de solda. Os resultados foram correlacionados com as microestruturas desenvolvidas tanto no metal de solda (MS) quanto na zona afetada termicamente (ZTA).
\end{abstract}

Palavras-chave: Nióbio. Metal de solda. Propriedades mecânicas.

\begin{abstract}
This study aims to evaluate the influence of $\mathrm{Nb}$ on the mechanical and microstructural properties of Strenx 700 steel weld metal obtained with FCAW-G process. Multipass welding was performed, with preheating of $120^{\circ} \mathrm{C}$ and interpass of $200^{\circ} \mathrm{C}$, in the flat position with welding energy ranging from $0,72,0,90,1,20 \mathrm{~kJ} / \mathrm{mmm}$. The addition material to be used is an electrode of E81T1 Nb G metallic soul, diameter 1,2 mm, associated to the gas protection of $\mathrm{CO}_{2}$. After welding were performed tensile tests, hardness, charpy-V notch, optical microscopy, microanalysis EDS and chemical analysis for mechanical and microstructural characterization of weld metal. The results will be correlated with the microstructures developed in both weld metal (WM) and in the heat affected zone (HAZ).
\end{abstract}

Keywords: Niobium. Weld metal. Mechanical properties.

\footnotetext{
II Estudante do Curso Superior de Tecnologia em Mecânica: processos de soldagem da Faculdade de Tecnologia (FATEC) de Sertãozinho - São Paulo - Brasil. E-mail: douglascolucci.7@gmail.com

II Prof. Esp./Mestrando da Faculdade de Tecnologia (FATEC) de Sertãozinho - São Paulo - Brasil. E-mail: acm.ventura@gmail.com

III Prof. Pós-Dra. da Faculdade de Tecnologia (FATEC) de Sertãozinho - São Paulo - Brasil. E-mail: mariaboverio@hotmail.com
} 
Data de submissão do artigo: 13/08/2020.

Data de aprovação do artigo: 15/10/2020.

DOI: $10.33635 /$ sitefa.v3i1.104

\section{INTRODUÇÃO}

Há muitos anos, o nióbio desempenha um importante papel reconhecidamente benéfico para o aumento simultâneo da resistência mecânica e da tenacidade, de metais de solda em aços de elevada tensão de escoamento. A maioria dos materiais de adição, as introduções de $\mathrm{Nb}$ não excedem 1000 ppm e com este teor o $\mathrm{Nb}$ é capaz de alterar a temperabilidade devido, tais fatores: controla o crescimento de grão e aumentam a tensão de escoamento sem decréscimo da tenacidade pelo mecanismo de refino de grão e precipitação, favorecendo a formação de microestrutura com a ferrita acicular (EVANS, 1993; BOSANSKY; EVANS, 1992).

Embora o $\mathrm{Nb}$ seja conhecido como sendo um elemento muito útil e o mais eficaz no refinamento de grão (ferrítico/austenítico), encontram-se estudos na literatura e publicações referentes à avaliação em profundidade dos mecanismos responsáveis pelo seu efeito, mas pouco com relação ao seu teor relacionado com as propriedades do metal de solda. Neste contexto, o grande desafio da soldagem, de um modo geral, na região da solda é obter níveis adequados com predominância de ferrita acicular (AF), os quais são fatores determinantes no desenvolvimento da microestrutura e na definição das propriedades mecânicas do metal de solda (JORGE et al., 2019). Na região da solda, tais propriedades são influenciadas diretamente pela composição química e pelo controle do processo de soldagem (VAZ; BRACARENSE, 2014; TRINDADE et al., 2004).

Pretende-se, nesse estudo, avaliar efeito do nióbio no comportamento microestrutural e das propriedades mecânicas do metal depositado da junta soldada de um aço temperado e revenido $-\mathrm{Q}+\mathrm{T}$. Atualmente os aços temperados e revenidos com microestrutura martensítica tem sido aplicado em chassis de carretas e semirreboques, guindastes, equipamentos de construção e agrícola, devido principalmente a sua elevada tensão de escoamento e tenacidade (SSAB, 2020). Nesses aços, é exigido operar em ambiente cada vez mais hostis como alta solicitação mecânica, baixas temperatura e meios agressivos, consequentemente, existe também a necessidade que a junta soldada, (MS e ZTA), tenham propriedades mecânicas semelhantes ao metal de base MB (ARSIC et al., 2015; DEBNATH; MUKHERJEE; PAL, 2014).

Entretanto, esses aços apresentam algumas limitações metalúrgicas devido às alterações provocada pelos ciclos térmicos de soldagem na região da ZTA, principalmente em razão da formação de martensita não revenida, a qual gera redução na tenacidade afetando negativamente a segurança operacional da junta soldada. Esta região é a mais crítica da junta, devido suas características fragilizantes. A esta prática está associada a presença de zonas descontinuas próximas a linhas de fusão, chamadas zona de transição (ZT) e zona de crescimento de grão (ZTAGG), que são frágeis, duras e responsáveis pela fragilização e perda das propriedades mecânicas da junta (QUITES, 2009).

No entanto, no estudo dos aços temperados e revenidos, a granulação excessivamente grosseira não é apenas o fenômeno de fragilização existente na ZTA, mas também ocorre o fenômeno de amolecimento causado pela queda abrupta da resistência na região intermediária da ZTA (ARSIC, et at., 2015; GÓRKA; KOTARSKA, 2019). Portanto, o estudo sobre aço de 


\section{(III) SITEFA}

elevada resistência deve não apenas ter atenção à fragilização pelo crescimento de grão, mas também ao amolecimento da zona afetada pelo calor (FARNEZE et al., 2009).

Sendo assim, o presente trabalho visa então correlacionar as diferentes microestruturas encontradas no metal de solda e zona termicamente afetada (ZTA), com as propriedades mecânicas da junta soldada. Como tal, a relação entre composição, microestrutura e desempenho é discutida combinada com as alterações microestruturais. Esses resultados fornecem uma base experimental para entender a influência da composição química e o desempenho do metal depositado.

\section{PROCEDIMENTOS METODOLÓGICOS}

Essa pesquisa caracteriza-se como bibliográfica e laboratorial.

\subsection{Material de base e consumíveis}

O material objeto deste estudo é o metal de adição AWS E81T1 Nb $1 \mathrm{G}$, sendo um arame tubular com fluxo, ou uma mistura de fluxo e pós metálicos com diâmetro de $1,2 \mathrm{~mm}$. A análise química do material de adição foi fornecida pelo fabricante do eletrodo, está disponível na Tabela 1.

Tabela 1 - Composição química do eletrodo desenvolvido para este estudo

\begin{tabular}{ccccccccc}
\hline $\begin{array}{c}\text { Especificação do } \\
\text { metal de adição }\end{array}$ & $\mathbf{C}$ & $\mathbf{S i}$ & $\mathbf{M n}$ & $\mathbf{P}$ & $\mathbf{S}$ & $\mathbf{N b}$ & Al & CET \\
\hline$E 81 T 1 \mathrm{Nb} 1 \mathrm{G}$ & 0,039 & 0,590 & 0,730 & 0,020 & 0,016 & 0,590 & 0,007 & 0,16 \\
\hline
\end{tabular}

Fonte: autoria própria (2019)

O material de base utilizado para este estudo foram chapas de aço estrutural temperado e revenido Strenx 700 Q\&T - Quenched and Tempered apresenta uma dureza média de 280 HV. A microestrutura do material de base é observada na Figura 1.

Figura 1 - Microestrutura martensítica revenida do aço Strenx 700

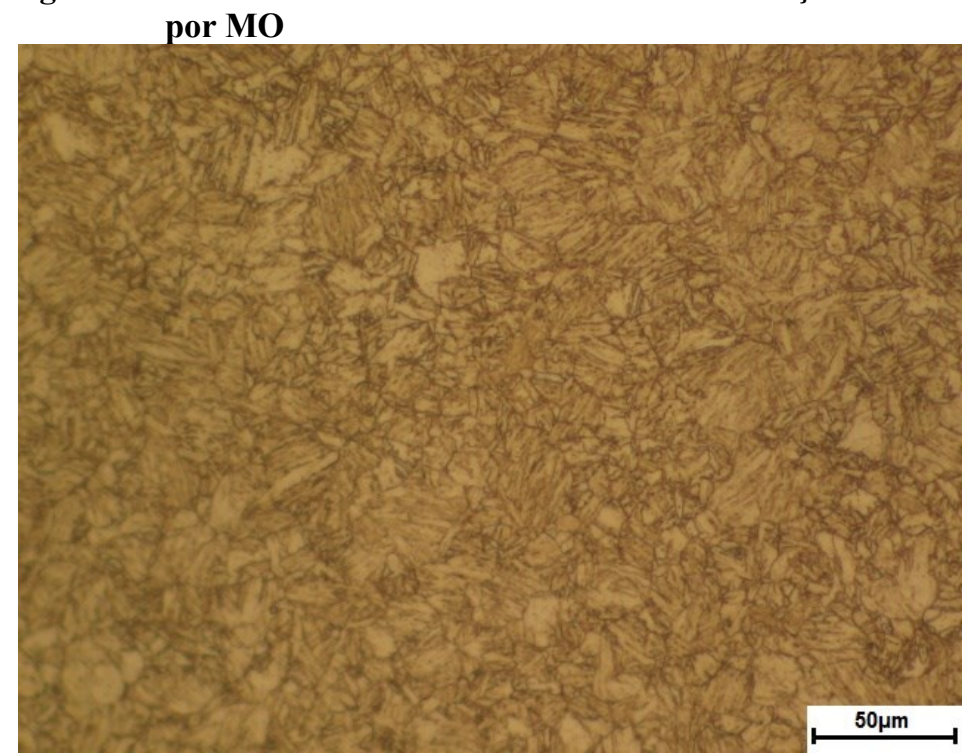

Fonte: autoria própria (2019) 


\section{(III) SITEFA}

Com base na microestrutura observada na Figura 1, a estrutura predominante é a martensita revenida caracterizada pelas regiões escuras e por microestruturas em forma de ripas e acicular. Esta microestrutura está de acordo com as publicações de Arsic, et at. (2015); Likes (2019), onde a composição química é semelhante à do aço em estudo. A composição química e as propriedades mecânicas do aço estão na Tabela 2.

Tabela 2 - A composição química e propriedades mecânicas típicas do aço Strenx 700

\begin{tabular}{|c|c|c|c|c|c|c|c|c|c|}
\hline \multicolumn{10}{|c|}{ Composição Química, teor em \% } \\
\hline C & $\mathbf{S i}$ & Mn & $\mathbf{P}$ & $\mathbf{S}$ & $\mathrm{Cr}$ & $\mathbf{C u}$ & $\mathbf{N i}$ & Mo & Bo \\
\hline$(\max )$. & (max.) & (max.) & (max.) & (max.) & (max.) & (max.) & (max.) & (max.) & $(\max )$. \\
\hline 0,20 & 0,60 & 1,60 & 0,020 & 0,010 & 0,80 & 0,30 & 2,00 & 0,70 & 0,005 \\
\hline
\end{tabular}

Propriedades Mecânicas, para corpos de prova transversais de acordo com a norma EN 10025-6

\begin{tabular}{cccccc}
\hline Espessura & CET(CEV) & $\begin{array}{c}\text { Limite de } \\
\text { escoamento }\end{array}$ & $\begin{array}{c}\text { Resistência à } \\
\text { tração }\end{array}$ & Alongamento & Charpy \\
\hline $\mathbf{m m})$ & $\mathbf{( \% )}$ & $\mathbf{R p 0 . 2 , [ M P a}]$ & $\mathbf{R m},[\mathbf{M P a}]$ & $\mathbf{A 5},[\%]$ & {$[\mathbf{J}], \mathbf{K V}$} \\
\hline $5,1-30,0$ & $0,32(0,49)$ & 700 & $780-930$ & 14 & $69 /-40^{\circ} \mathrm{C}$ \\
\hline
\end{tabular}

Fonte: SSAB (2020)

\subsection{Procedimento experimental}

Tabela 3 - Confecção e caracterização das juntas soldadas

\section{Preparação da junta a ser soldada}

\begin{tabular}{|c|c|}
\hline Geometria do chanfro & Detalhe da junta soldada \\
\hline \multicolumn{2}{|l|}{$\alpha$} \\
\hline \multicolumn{2}{|l|}{$\rightarrow-c$} \\
\hline \multicolumn{2}{|c|}{ Procedimento de soldagem } \\
\hline Consumível & Detalhe da peça soldada com E81T1 Nb 1G \\
\hline $\mathrm{E} 81 \mathrm{~T} 1 \mathrm{Nb} 1 \mathrm{G}$ & \multirow{4}{*}{ 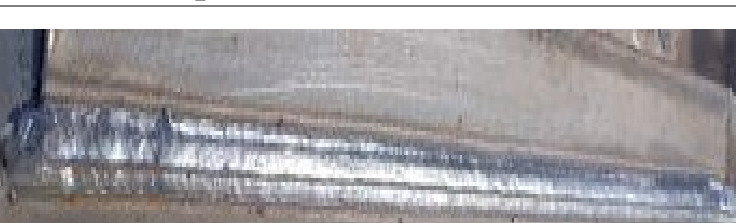 } \\
\hline Metal base & \\
\hline Espessura do MB & \\
\hline Diâmetro do arame & \\
\hline Gás de proteção $\quad \mathrm{CO}_{2}$ & \\
\hline Corrente/Polaridade $\mathrm{CC}+$ & \\
\hline Stick out $\quad 12(\mathrm{~mm})$ & \\
\hline
\end{tabular}

Fonte: Górka et at. (2019, p. 3) - adaptado pelos autores 


\section{(III) SITEFA}

As chapas utilizadas no processo de soldagem FCAW-G foram preparadas com as seguintes especificações: chapas de aço Strenx 700 de seções retangulares com dimensões nominais de $19 \mathrm{~mm}$ de espessura, $500 \mathrm{~mm}$ de comprimento e $150 \mathrm{~mm}$ de largura, respectivamente. A junta de topo, chanfro em $\mathrm{V}$ de $60^{\circ}$ e com abertura de raiz de $3 \mathrm{~mm}$. Todos os cordões de solda foram depositados com ângulo de trabalho de $90^{\circ}$ utilizando uma máquina de corte portátil (tartaruga) marca CONDOR modelo MQ1 30 para deslocamento da tocha, com distância bico de contato - peça ("stick-out") de $12 \mathrm{~mm}$. O pré-aquecimento foi definido a $120^{\circ} \mathrm{C}$, através de chama oxiacetilênica, e posteriormente foi realizada a soldagem multipasse depositando cinco camadas, com uma temperatura de interpasses de $200{ }^{\circ} \mathrm{C}$, e as condições de controle do pré-aquecimento e da temperatura entre passes foi realizado através de pirômetro. Os parâmetros de soldagem são mostrados na Tabela 4. O aporte térmico foi calculado de acordo com a literatura (QUITES, 2009; SSAB, 2020).

Tabela 4 - Parâmetros do processo de soldagem FCAW-G

\begin{tabular}{lcccccc}
\hline Passes & $\begin{array}{c}\text { Temperatura } \\
\text { pré- } \\
\text { aquecimento }\end{array}$ & $\begin{array}{c}\text { Temperatura } \\
\text { interpasse }\end{array}$ & Corrente & Tensão & Velocidade & $\begin{array}{c}\text { Aporte } \\
\text { de Calor }\end{array}$ \\
\hline $1^{\circ}(\mathrm{Raiz})$ & $\left({ }^{\circ} \boldsymbol{C}\right)$ & $\left({ }^{\circ} \boldsymbol{C}\right)$ & $(\boldsymbol{A})$ & $(\boldsymbol{V})$ & $(\mathbf{m m} / \mathbf{m i n})$ & $(\boldsymbol{K J} / \mathbf{m m})$ \\
\hline $2^{\circ}, 3^{\circ}, 4^{\circ}$ & 120 & 200 & 180 & 28 & 200 & 1,20 \\
\hline $5^{\circ}, 6^{\circ}, 7^{\circ}$ & 120 & 200 & 180 & 28 & 200 & 1,20 \\
\hline $8^{\circ}, 9^{\circ}, 10^{\circ}$ & 120 & 200 & 170 & 28 & 250 & 0,91 \\
\hline
\end{tabular}

Fonte: autoria própria (2019)

\subsection{Confecção dos corpos de prova e realização dos ensaios}

Para a caraterização do metal depositado foi retirada amostra no sentido transversal tomando-se toda a espessura, após preparação metalográfica convencional foram submetidas ao ataque químico. Neste ponto foram examinadas em microscópio óptico (MO) as zonas (MB, MS e ZTA), a fim de se caracterizar influência do metal de solda nas microestruturas existentes. A análise química e microanálise por espectroscopia de energia dispersiva (EDS) foi realizada, com o objetivo de identificar qualitativamente a composição das fases presentes de um certo ponto na zona fundida $(\mathrm{ZF})$, permitindo que se correlacione à $\mathrm{MO}$ com informações da composição detalhada.

Figura 2 - Perfil para medição da dureza

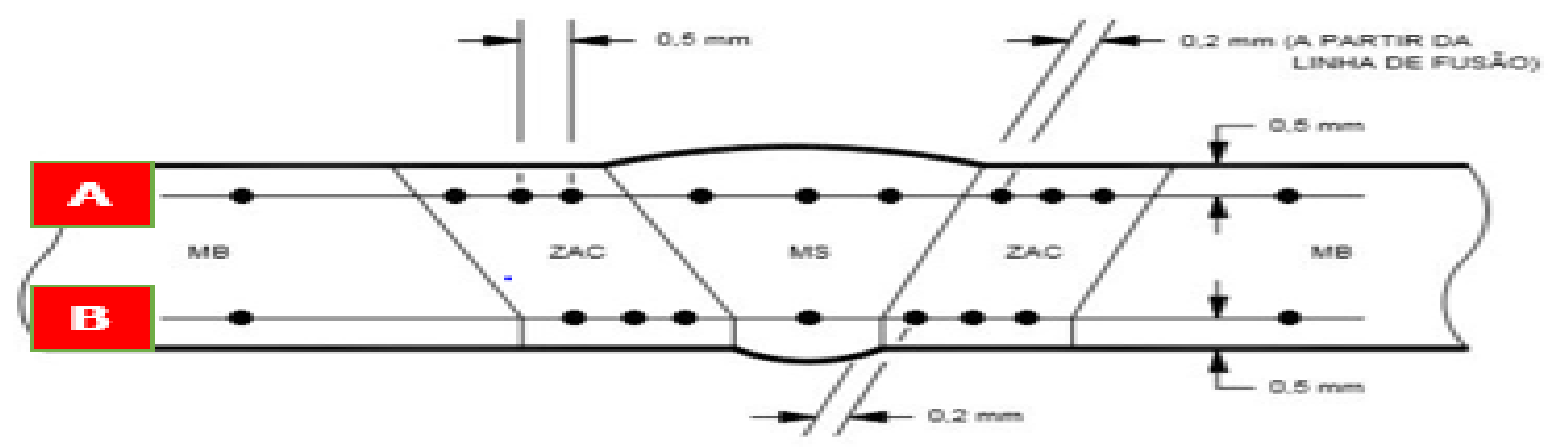

Fonte: Petrobras N-133 (2002, p. 10) - adaptado pelos autores 


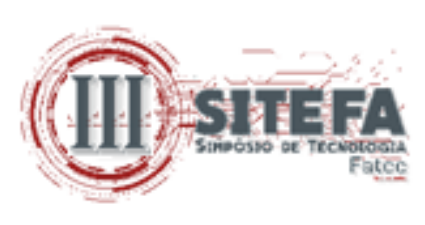

Os ensaios de dureza Vickers foram efetuados segunda a Norma Petrobras N-0133 no equipamento digital PANTEC, modelo MV2000 do laboratório de ensaios mecânicos da FATEC. Para o levantamento do perfil de microdureza da junta soldada, a amostra foi cortada para a retirada de uma seção transversal. Em uma linha horizontal A e B, como mostrado na Figura 2, foram executadas 20 medidas de microdureza com valor de carga de $1 \operatorname{Kgf}(9,8 \mathrm{~N})$ durante 50 segundos aproximadamente. Os parâmetros utilizados no ensaio de microdureza são apresentados na Figura 2.

Foram realizados ensaios de tração com o equipamento SHANDONG, modelo WDW100EB, segundo as normas ASTM A370 e ASTM E8M. Esses ensaios foram realizados na FATEC Sertãozinho à temperatura ambiente com capacidade máxima de 100 KN. Foram ensaiados, para cada condição avaliada, três corpos de prova (CPs) de seção circular nas direções L (1 PC longitudinal) e T (2 PCs transversal) em relação a solda. A caracterização mecânica em tração foi feita em termos de limite de escoamento $(\mathrm{Rp} 0,2 \mathrm{MPa})$, limite de resistência ( $\mathrm{Rm} \mathrm{MPa)} \mathrm{e} \mathrm{alongamento} \mathrm{total} \mathrm{(A \% ).}$

$\mathrm{O}$ ensaio de impacto Charpy $\mathrm{V}$ foi realizado na FATEC Sertãozinho, seguindo a norma ASTM A370-12 e ASTM E23-16, à temperatura de $+20^{\circ} \mathrm{C}$, em 6 corpos de prova com entalhe em $\mathrm{V}$ de duas zonas diferentes (metal fundido e zona termicamente afetada); as dimensões dos PCs $(10 \times 10 \times 55 \mathrm{~mm})$ e o posicionamento dos entalhes foram definidos com base na norma BS EN 10045-1:1990. Os entalhes foram posicionados ao centro do cordão de solda, na linha de fusão e na zona afetada pelo calor.

\section{RESULTADOS E DISCUSSÃO}

Os resultados e as discussões serão apresentados nas subseções a seguir.

\subsection{Análise química e EDS}

Os resultados obtidos na análise química do metal de base e metal depositado estão apresentados na Tabela 5 e 6 . Os resultados obtidos foram comparados com os valores especificados na literatura (Tabela 5), sendo confirmado que todos os elementos se encontraram dentro dos valores estipulados pela norma EN 10025-6.

Tabela 5 - Análise química do aço Strenx 700 com espessura nominal de 19 mm

Composição Química do MB, teor em (\%)

\begin{tabular}{cccccccccc}
\hline $\mathbf{C}$ & $\mathbf{S i}$ & $\mathbf{M n}$ & $\mathbf{P}$ & $\mathbf{S}$ & $\mathbf{C r}$ & $\mathbf{N i}$ & $\mathbf{M o}$ & $\mathbf{A l}$ & CET \\
\hline $\mathbf{0 , 1 5 8 0}$ & 0,3130 & 1,2300 & 0,0081 & 0,0013 & 0,2660 & 0,0790 & 0,1480 & 0,0610 & \multirow{2}{*}{0,47} \\
\cline { 1 - 1 } $\mathbf{C u}$ & $\mathbf{C o}$ & $\mathbf{T i}$ & $\mathbf{N b}$ & $\mathbf{V}$ & $\mathbf{W}$ & $\mathbf{P b}$ & $\mathbf{B}$ & $\mathbf{S n}$ & \\
\hline $\mathbf{0 , 1 3 8 0}$ & 0,0068 & 0,0140 & 0,0130 & 0,0320 & $<0,010$ & 0,0045 & 0,0013 & 0,0018 \\
\hline $\mathbf{Z n}$ & $\mathbf{A s}$ & $\mathbf{B i}$ & $\mathbf{C a}$ & $\mathbf{C e}$ & $\mathbf{Z r}$ & $\mathbf{L a}$ & \multicolumn{2}{|c|}{$\mathbf{F e}$} & \\
\hline$<\mathbf{0 , 0 0 2 0}$ & 0,0023 & 0,0059 & 0,0016 & $<0,0030$ & $<0,0015$ & $<0,0010$ & 97,5 & \\
\hline
\end{tabular}

Fonte: autoria própria (2019)

De salientar a baixos níveis de carbono, característica dos aços de baixa liga produzidos pelo processo (temperado e revenido- Q\&T) e, consequente, baixo carbono equivalente, possibilitando uma boa soldabilidade. Outro fator importante, detectado na análise química, foram as quantidades encontradas de manganês (Mn) como elemento majoritário e ainda traços de nióbio $(\mathrm{Nb})$, titânio $(\mathrm{Ti})$, vanádio $(\mathrm{V})$ e molibdênio $(\mathrm{Mo})$, além 


\section{(III) SIIEFA}

dos elementos desoxidantes, oxigênio $(\mathrm{O})$, carbono $(\mathrm{C})$ e ferro $(\mathrm{Fe})$, fósforo $(\mathrm{P})$, enxofre $(\mathrm{S})$, silício $(\mathrm{Si})$, cálcio $(\mathrm{Ca})$ e alumínio $(\mathrm{Al})$ em sua composição. Esses elementos químicos, associados ao processo de fabricação, contribuem para as excelentes propriedades mecânicas, para esses materiais, apesar da quantidade de carbono (C) ser relativamente baixa. A soldabilidade nesses pode ser avaliada empiricamente a partir do cálculo do Carbono Equivalente (CET). No caso do aço Strenx 700, com vários elementos de liga, a fórmula recomendada pelo Instituto Internacional de Soldadura, é a seguinte: $\mathrm{CET}=\mathrm{C}+\mathrm{Mn} / 6+$ $(\mathrm{Cr}+\mathrm{Mo}+\mathrm{V}) / 5+(\mathrm{Ni}+\mathrm{Cu}) / 15[\%]$

A Tabela 6 apresenta a composição química do metal de solda depositado. Através de análise comparativa, é possível observar que o metal depositado apresenta teores de (P), (S), $(\mathrm{Si})$ e $(\mathrm{Nb})$ superiores ao metal de base. Ainda, de forma inversa, os teores de $(\mathrm{C})$ e $(\mathrm{Mn})$ são inferiores.

Tabela 6 - Análise química nominal real do metal depositado

\begin{tabular}{ccccccccc}
\hline \multicolumn{7}{c}{ Composição química do metal depositado, teor em (\%) } \\
\hline $\mathbf{C}$ & $\mathbf{S i}$ & $\mathbf{M n}$ & $\mathbf{P}$ & $\mathbf{S}$ & $\mathbf{C r}$ & $\mathbf{N i}$ & $\mathbf{M o}$ & $\mathbf{A l}$ \\
\hline 0,0470 & 0,4590 & 0,5900 & 0,0093 & 0,0110 & 0,0350 & 0,1410 & 0,0037 & 0,0049 \\
\hline $\mathbf{C u}$ & $\mathbf{C o}$ & $\mathbf{T i}$ & $\mathbf{N b}$ & $\mathbf{C e}$ & $\mathbf{Z r}$ & $\mathbf{L a}$ & $\mathbf{C a}$ & $\mathbf{B i}$ \\
\hline 0,0230 & $<0,0021$ & 0,0230 & 0,3210 & $<0,0030$ & $<0,0015$ & $<0,0010$ & 0,0006 & 0,0071 \\
\hline $\mathbf{V}$ & $\mathbf{W}$ & $\mathbf{P b}$ & $\mathbf{B}$ & $\mathbf{S n}$ & $\mathbf{Z n}$ & $\mathbf{A s}$ & \multicolumn{2}{|c}{$\mathbf{F e}$} \\
\hline 0,0170 & $<0,010$ & 0,0044 & 0,0024 & 0,0010 & $<0,0020$ & 0,0059 & \multicolumn{2}{c}{98,3} \\
\hline
\end{tabular}

Fonte: autoria própria (2019)

A Figura 3, mostram picos que sugerem da presença de precipitados do tipo carbonetos/carbetos de nióbio e segregações que pode ser uma mistura de óxidos de Al, Si e Mn, e outros desoxidantes foram observados e podem causar segregações de impurezas como $\mathrm{Ca}, \mathrm{S}$ e $\mathrm{P}$ nos contornos de grão da austenita previa. Na Figura 3 é mostrado o mapeamento por EDS realizado no metal de solda do Strenx 700.

Figura 3 - a) Mapeamento de composição; b) Espectro por EDS dos elementos presentes na diluição do metal depositado

a)

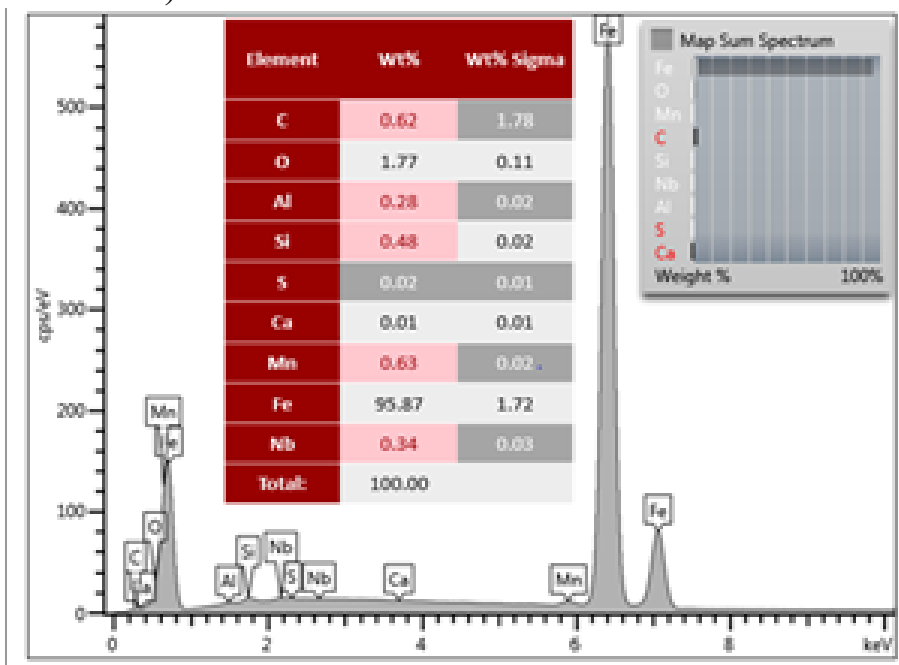

b)

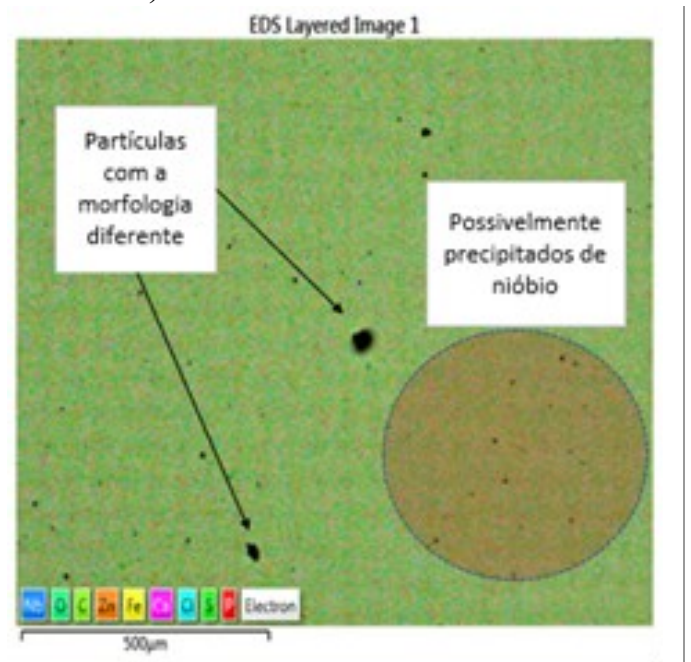

Fonte: autoria própria (2019) 


\section{(III) SITEFA}

Ficou evidenciado a presença de C, O, Fe, P, S, Si, Mn, Ca, Nb e Al. De acordo com o mapeamento de composição dos elementos, espectro da análise de EDS e análise semiquantitativa (a), (b), Figura 3. Constatou-se que assim como verificado na composição química do metal de solda, a diluição não foi eficiente. Pela análise de EDS, pode dizer-se que, teoricamente, o aumento da resistência, nesta investigação, está associado a teores de C, $\mathrm{Si}, \mathrm{Fe}$ e $\mathrm{Mn}$ mais altos (endurecimento por solução sólida), bem como, a teores de $\mathrm{Nb}$ e $\mathrm{O}$ mais elevado (endurecimento por precipitação); por sua vez, a quantidade de $\mathrm{P}$ e S tem maior influência na ductilidade, afetando negativamente as propriedades (devido à formação de inclusões).

\subsection{Caracterização da junta soldada}

Para a caracterização da junta soldada, foram realizadas indentações de microdureza, apesar de simples, traz informações importantes para determinação das características metalúrgicas e mecânicas da junta soldada do aço Strenx 700. Na Figura 4, para a soldagem FCAW-G, observam-se o perfil de dureza Vickers (HV1), que foi realizado ao longo de toda a junta soldada varrendo as regiões compreendidas pelo metal de base (MB), zona afetada pelo calor (ZTA) e metal de solda (MS). Como visto na Figura 4, o valor da dureza demostra uma acentuada variação ao longo da junta soldada entre as linhas A e B devido ao aporte térmico na soldagem multipasses. Esse fenômeno é causado pelo aquecimento rápido durante o processo de soldagem, seguido por severas taxas de resfriamento. Essa variação térmica pode alterar a microestrutura da solda e influenciar a dureza do produto. Nesse caso, o gráfico da Figura 4 e a Tabela 7, apresentam os valores de dureza medidos no MS na condição como soldado está exibido o valor médio de $298 \mathrm{HV}$, apresentando máximo de $326 \mathrm{HV}$, havendo, contudo, uma tendência para um menor valor de dureza na raiz $245 \mathrm{HV}$, o que pode ser atribuído ao ciclo de reaquecimento da soldagem multipasse.

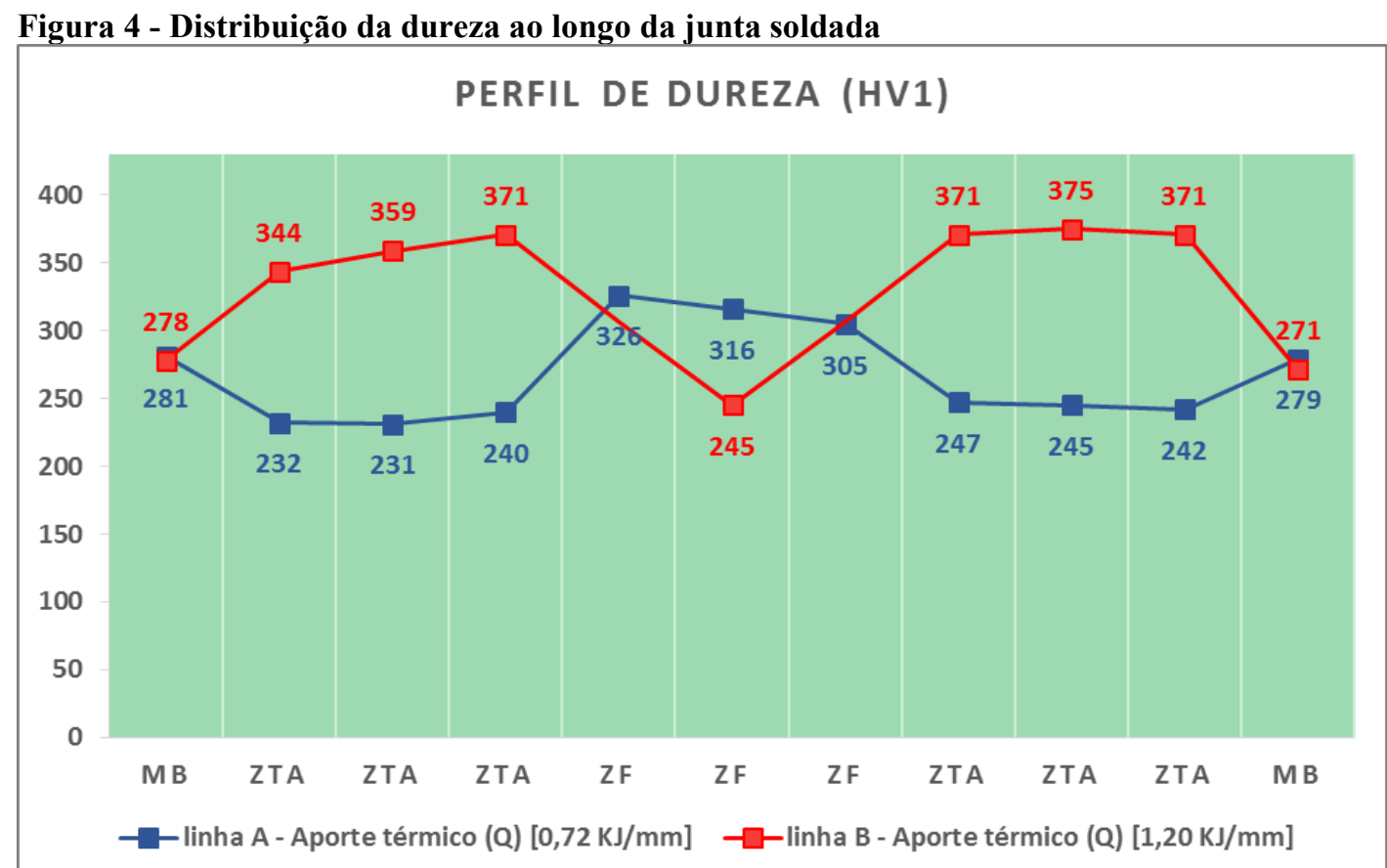

Fonte: autoria própria (2019) 


\section{(III) SIIEFA}

Os valores de dureza encontrados no MB ficaram entre 271 e $281 \mathrm{HV}$, com média 277 HV o que está de acordo com a literatura (ARSIC, et at. ,2015 e LIKES, 2019). Na ZTA, o valor médio encontrado foi de $302 \mathrm{HV}$, com valor máximo de $375 \mathrm{HV}$ e mínimo de $231 \mathrm{HV}$ com desvio padrão $66 \mathrm{HV}$. Na Figura 4 pode-se perceber que a dureza da ZTA é superior à do MB e à do MS. O aumento de dureza na região recristalizada da ZTA do aço Strenx 700, no estado como soldado atribui-se ao refinamento de grão, dissolução de carbonetos e formação de martensita e bainita inferior (ARSIC, et at., 2015).

Tabela 7 - Resultados do mapeamento ao longo da junta soldada

\begin{tabular}{cccc}
\hline \multicolumn{5}{c}{ Petrobras N133: Indentações de Dureza (HV1) } \\
\hline Regióes & MB & ZTA & MS \\
\hline Máximo & 281 & 375 & 326 \\
\hline Mínimo & 271 & 231 & 245 \\
\hline Média & 277 & 302 & 298 \\
\hline Desvio Padrão & 4 & 66 & 36 \\
\hline
\end{tabular}

Fonte: autoria própria (2019)

Também é notório o decréscimo do valor de dureza na região ICZTA ficando entre 231 e $242 \mathrm{HV}$. Fica evidente também, conforme maior o tamanho grão da ZTA, maior a dispersão de resultados encontrados e consequentemente maior o desvio padrão para análise estatística.

Figura 5 - Caracterização da zona de fusão (ZF) e da zona afetada (ZTA)

a) $\mathbf{Z F}$

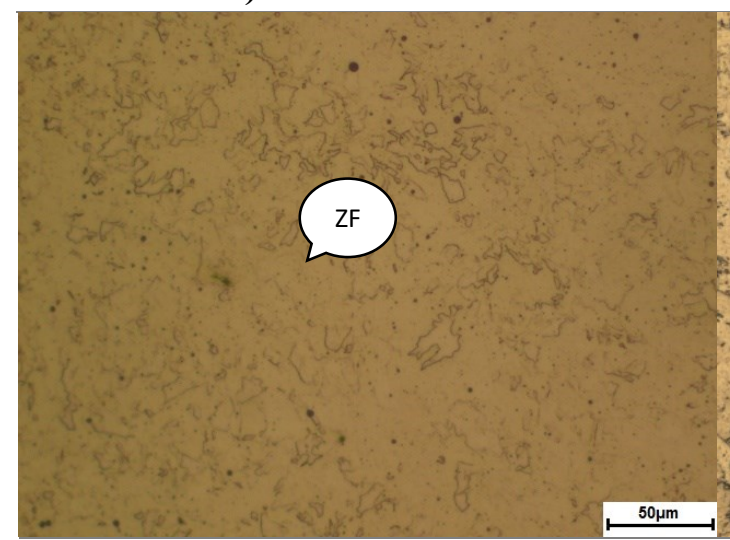

c) ZF e ZTA

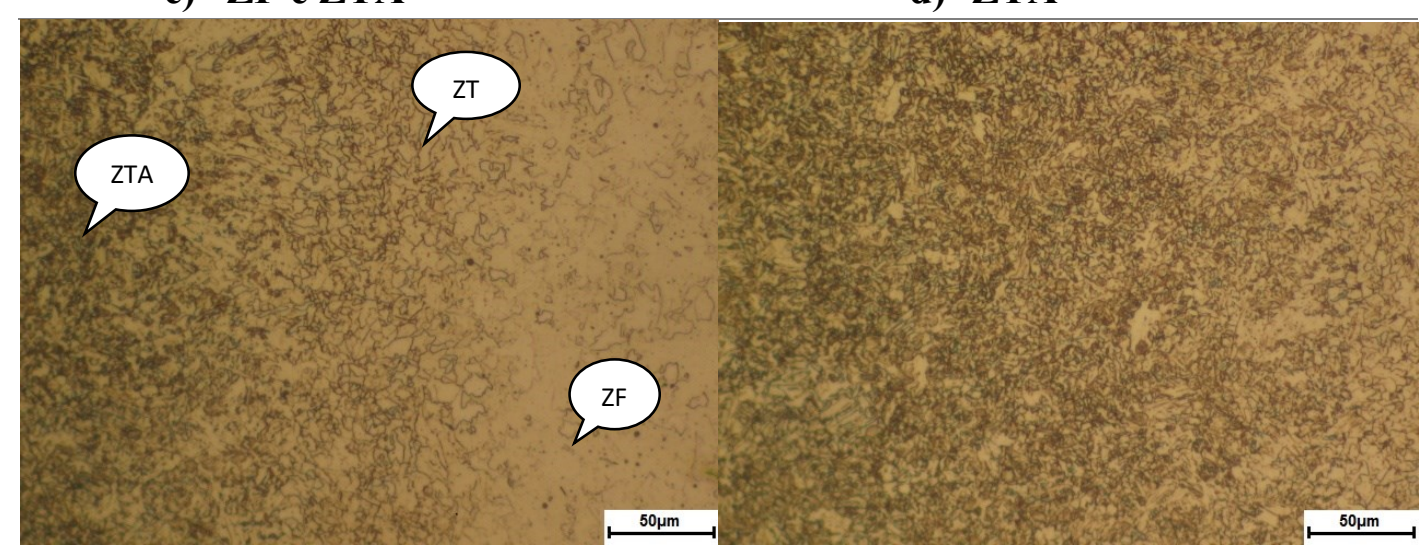

b) ZF e ZTA

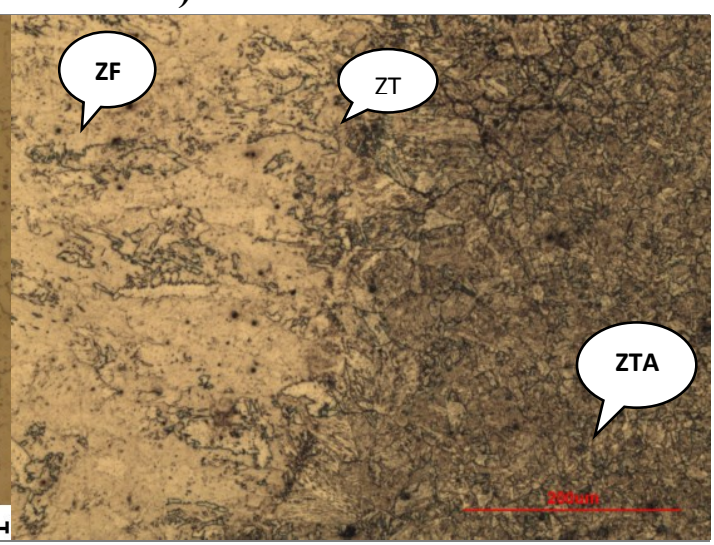

d) ZTA

Fonte: autoria própria (2019) 
$\mathrm{Na}$ Figura 5 mostram as microestruturas das regiões mais importante para análise, ou seja, zona afetada de granulação grosseira (ZTAGG) e zona de fusão (ZF), obtida por (MO) com aumento de (100X. 200X.), onde se notam as seguintes características principais:

I. A microestrutura da $\mathrm{MB}$ é constituída predominantemente por martensita revenida (Figura 1).

II. Na Figura 5 (a), (b), (c) e (d), é evidenciada a provável presença de ferrita poligonal PF, ferrita desalinhada com carbonetos FS (NA), ferrita alinhada com carbonetos FS (A) e ferrita com carbonetos agregados (FC), além de microconstituintes M-A.

III. Verifica-se ZTAGG a existência de uma variação microestrutural devido à soldagem multipasse, onde ocorreu significativa formação do microconstituinte M-A. Este resultado é provavelmente devido à utilização de um aporte térmico relativamente elevado $(1,20 \mathrm{KJ} / \mathrm{mm})$ e uma temperatura de interpasse maior, o que influenciam no tamanho de grão austenítico, já que ocorre uma taxa de resfriamento menor e um aumento do tempo de permanência possibilitando a decomposição do microconstituinte M-A em detrimento a redução da tenacidade nesta região da junta soldada.

IV. Já, no caso da ZF verifica-se um aumento das áreas ferríticas com coalescimento dos carbonetos e provável ocorrência de microfases.

V. A avaliação EDS da composição química do metal de solda referente ao procedimento de soldagem, presumidamente apresentou um maior percentual de $\mathrm{C}$, em detrimento do teor elevado de $\mathrm{Nb}$ e do baixo teor de $\mathrm{Mn}$, contribuindo para maior formação de agregados de ferrita-carbonetos (FC) (EVANS, 1993; BOSANSKY et at., 1992).

\subsection{Ensaio de Tração do Metal de Solda}

Na Figura 6, são apresentados os resultados do limite de escoamento Rp0,2 (Mpa), da resistência à tração $\mathrm{Rm}(\mathrm{Mpa})$ e do alongamento $\mathrm{A}(\%)$ a partir dos dados dos ensaios de tração para cada corpo de prova específico, juntamente com o critério de aceitação utilizado que é referente ao MB para acessórios de ancoragem, onde se notam as seguintes características principais:

I. Na Figura 6 evidencia-se que as amostras apresentaram abaixo percentuais de alongamento (A\%), o que está de acordo com os valores encontrados nos ensaios de impacto. De acordo com Evans (1993) dependendo do teor de $\mathrm{Nb}$, a resistência do metal de solda fica reduzida pela formação de microfases frágeis tipo MA e pela precipitação de $\mathrm{Nb}(\mathrm{C}, \mathrm{N})$, onde proporcionam uma baixa resistência à propagação de trincas prejudicando a tenacidade e a resistência mecânica dos metais de solda (BOSANSKY, et at.,1992).

II. Verifica-se que o metal de solda não atende aos requisitos especificados para aço grau Strenx 700 para todas as condições de análise;

III. De salientar que a fratura dos corpo-de-prova ocorreu sempre no metal de solda, a queda das propriedades mecânicas da solda está relacionada com a composição química do metal de adição que apresenta carbono equivalente CET inferior ao MB. Esta diferença contribui para o desbalanceamento das fases gerando segregação e precipitação nos contornos de grão afetando negativamente esta região;

IV. Todos os valores de Rp0,2, A e Rm estão inferiores aos mínimos requeridos. $\mathrm{Na}$ Figura 6 verifica-se que os resultados dos ensaios de tração não atingem os valores especificados pelo $\mathrm{MB}$ para o limite de escoamento $(690-700 \mathrm{MPa})$, resistência à tração (760 $\mathrm{MPa})$ e alongamento (12\%). 


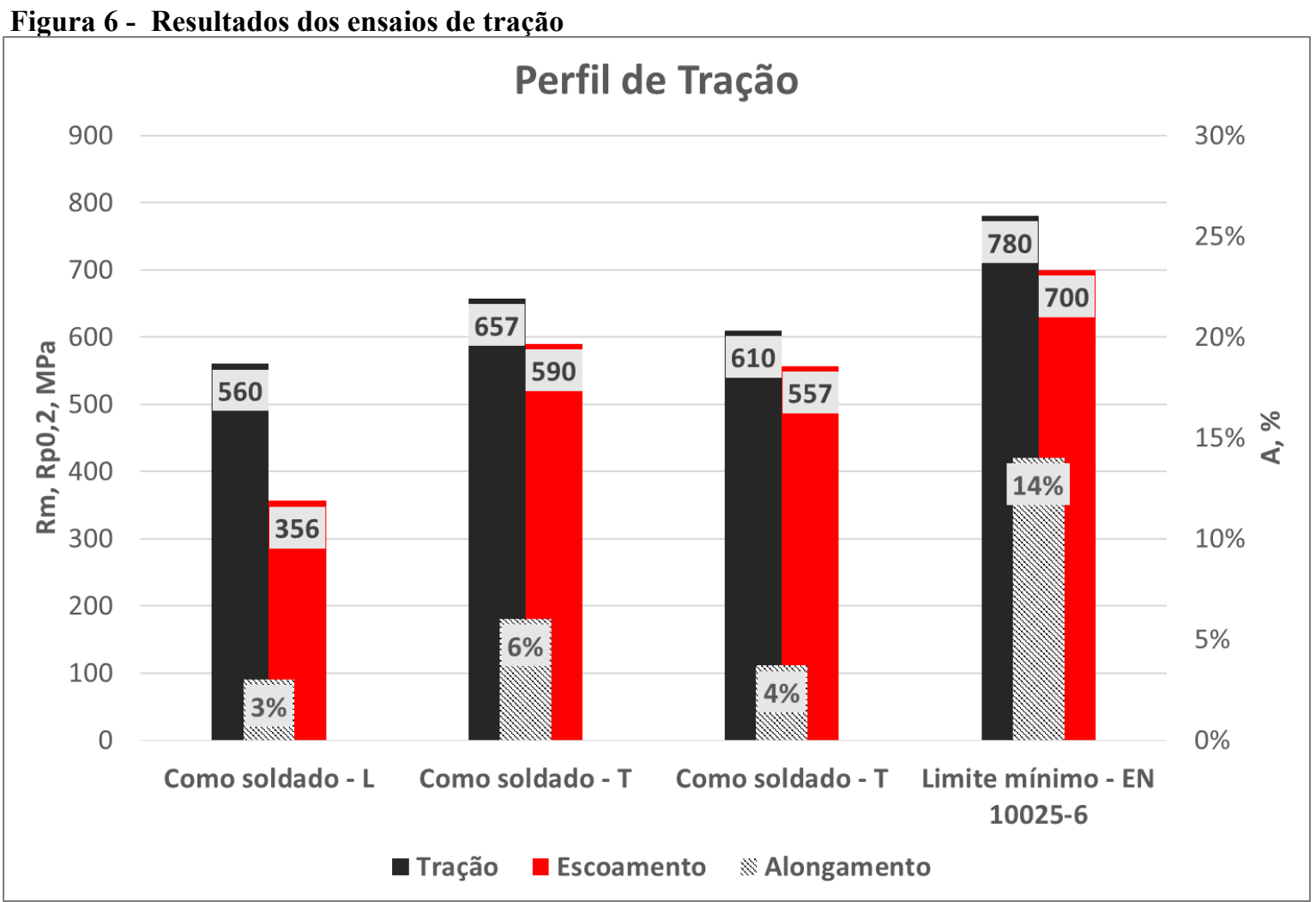

Fonte: autoria própria (2019)

\subsection{Ensaio de impacto do metal de solda}

Na Figura 7 é possível observar os resultados encontrados com base nos ensaios de impacto Charpy $\mathrm{V} \mathrm{a}+20^{\circ} \mathrm{C}$ realizados no metal de solda e na ZTA para as amostras da Tabela 3 , juntamente com o critério de aceitação utilizado para (200 Joules - MB), a avaliação da tenacidade ao impacto pode ser feita, com base nas seguintes evidências:

I. A Figura 8 representa a superfície de fratura observada nos corpos de prova de impacto. Na ZF, observa-se a presença de fratura frágil. Já, ZTA, apresenta um aspecto de fratura mista frágil/dúctil. Em ambas as regiões, as fraturas das amostras apresentam superfície brilhante (no centro e na lateral) e fosca nas bordas (área de cisalhamento) com possibilidade de fratura por clivagem.

II. Na Figura 7 verifica-se uma acentuada queda da tenacidade. Em ambos as regiões (MS e ZTA) apresentam resultados inferiores aos mínimos especificados para aço grau Strenx 700, conforme a Norma EN 10025-6. Comparando-se esses resultados com o patamar mínimo de $200 \mathrm{~J}$ observa-se que todas as condições em estudo apresentam resultados insatisfatório;

III. Os resultados decrescentes evidenciam que ambos as regiões (MS e ZTA) podem, presumivelmente, estar relacionada com as alterações microestruturais, já que ele apresenta grande incidência de microconstituinte A-M que provoca efeito prejudicial à tenacidade; 


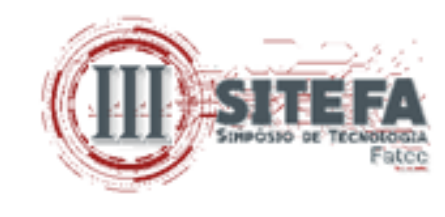

Figura 7 - Resultados dos ensaios de impacto Charpy-V realizados à $+20^{\circ} \mathrm{C}$, em Joules

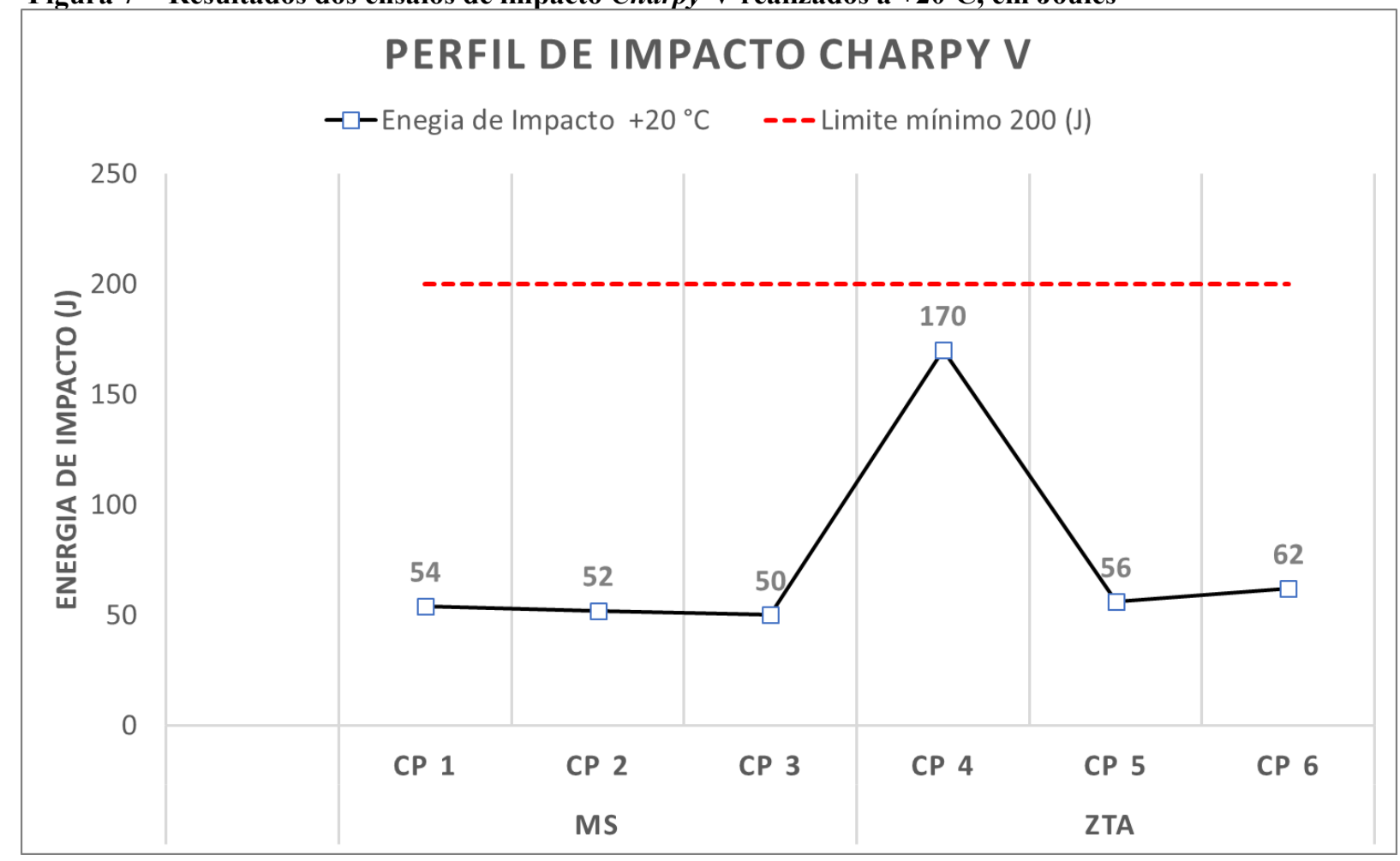

Fonte: autoria própria (2019)

Figura 8 - Amostras após ensaio de impacto Charpy

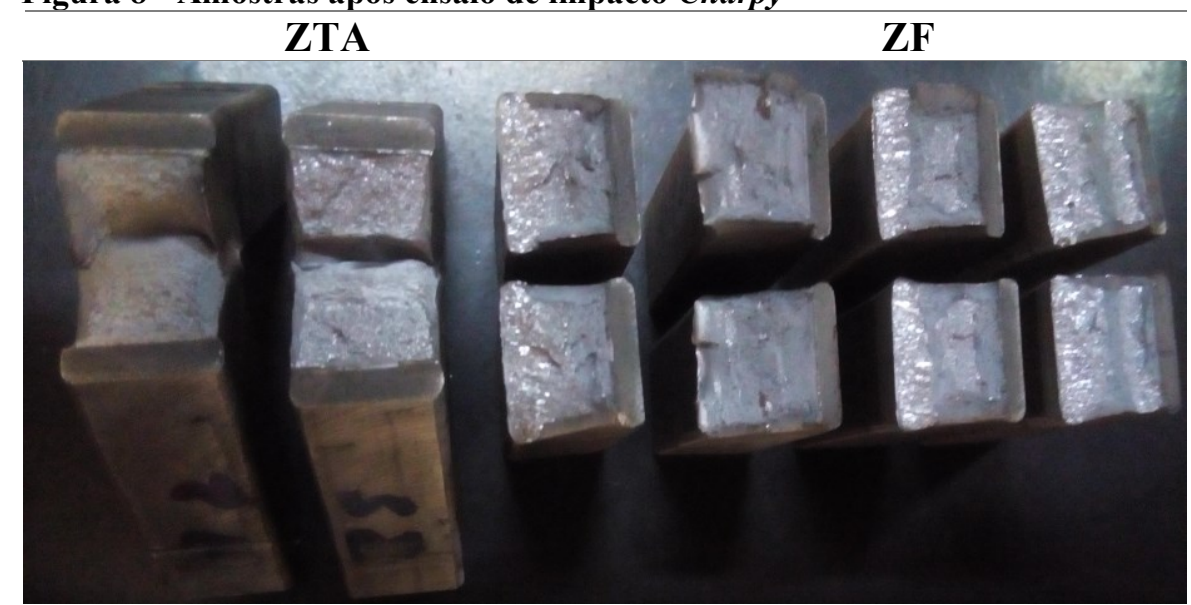

Fonte: autoria própria (2019)

\section{CONCLUSÃO}

Os resultados deste trabalho permitem apresentar as seguintes conclusões com relação à soldagem do aço Strenx ${ }^{\circledR} 700$ com o metal de adição E81T1 Nb 1G:

A variação no comportamento microestrutural e da tenacidade do metal de solda e da ZTA estão diretamente relacionadas com as variações ocorridas na energia de soldagem. A microestrutura da ZTA apresenta uma granulação grosseira (GGZTA). Este elevado tamanho de grão reflete diretamente na queda da tenacidade. 
Verificou-se que a queda da resistência mecânica do metal depositado em todos os ensaios está fora das especificações do material de base. Este fato, está associado as variações micro estrutural e, também, ao metal de adição utilizado, que pelo comportamento apresentado, mostrou não ser adequado para a soldagem desta classe de aço nas condições empregadas nesta investigação.

\section{REFERÊNCIAS}

ARSIC, D., et al.. Optimal welding technology of high strength steel S690QL. Materials Engineering - Materiálové inžinierstvo (MEMI), 22(1), 33-47. 2015. Disponível em: http://ojs.mateng.sk/index.php/Mateng/article/view/165. Acesso em: 06 jun. 2020.

BOSANSKY, J.; EVANS, G. M.. Relationships between the properties of weld metals microalloyed with $\mathrm{v}$ and $\mathrm{nb}$, their structure and substructure. Welding International, 6(12), 997-1002. 1992. Disponível em: https://doi.org/10.1080/09507119209548332. Acesso em:06 jun. 2020.

DEBNATH, S.; MUKHERJEE, M.; PAL, T.. Study on Microstructure and Mechanical Properties of Thick Low-Alloy Quench and Tempered Steel Welded Joint. Materials Performance and Characterization, 3(1), 23-48. 2014. Disponível em: https://doi.org/10.1520/MPC20130028. Acesso em: 06 jun. 2020.

EVANS, G. M.. Effects of niobium in manganese containing mma weld deposits. Welding International, 7(7), 518-528. 1993. Disponível em: https://doi.org/10.1080/09507119309548437. Acesso em: 06 jun. 2020.

FARNEZE, Humberto N. et al. Estudo comparativo de metais de solda de aço de alta resistência obtidos pelos processos eletrodo revestido e arame tubular para aplicação em equipamentos de amarração offshore. Soldag. insp. (Impr.) [online]. 2009, vol.14, n.2, pp.151-160. ISSN 1980-6973. Disponível em: https://doi.org/10.1590/S010492242009000200007. Acesso em: 06 jun. 2020.

GÓRKA, J.; KOTARSKA, A.. MAG welding of 960QL quenched and tempered steel. IOP Conference Series: Materials Science and Engineering, 591(6), 012017. 2019. Disponível em: https://doi.org/10.1088/1757-899X/591/1/012017. Acesso em: 07 jun. 2020.

JORGE, J.C.F., et al. Mechanical and microstructural behavior of C-Mn steel weld deposits with varying titanium contents. Journal of Materials Research and Technology, 8(8), 46594671. 2019. Disponível em: https://doi.org/10.1016/j.jmrt.. Acesso em: 08 out. 2019.

LIKES, M. A. K. (2019). Investigação de desvios geométricos na furação de aço avançado de alta resistência Strenx ${ }^{\circledR} 700$ com ferramentas de aço-rápido revestidas. Trabalho de Conclusão de Curso (Graduação), Guarapuava, PR: UTFPR, Brasil. Disponível em: http://repositorio.roca.utfpr.edu.br/jspui/handle/1/11622. Acesso em: 02 jun. 2020

PETROBRAS N-133. Soldagem. Disponível em: https://www.docsity.com/pt/n-01331/4830275/. Acesso em: 14 jun. 2020. 
QUITES, A. M. Metalurgia na soldagem dos aços. 2 ed. Florianópolis: Solda soft. 2009.

SSAB. Strenx ${ }^{\circledR} 700$ - O aço estrutural de alta resistência com 700 MPa. 2020. Disponível em: https://www.ssab.com.br/products/brands/strenx/products/strenx-700. Acesso em: 09 jun. 2020

TRINDADE FILHO, V.B., et al. Normalizing heat treatment effect on low alloy steel weld metals. Journal of the Brazilian Society of Mechanical Sciences and Engineering, 26(1), 62-66, 2004. Disponível em: https://dx.doi.org/10.1590/S1678-58782004000100011. Acesso em: 06 jun. 2020.

VAZ, C. T.; Bracarense, A. Q.. Influência do uso de PTFE como aglomerante em eletrodos revestidos básicos sobre a formação de ferrita acicular no metal de solda. Soldagem \& Inspeção, 19(2), 177-189, 2014. Disponível em: https://doi.org/10.1590/01049224/SI1902.10. Acesso em 06 jun. 2020. 